\title{
The progression from disaster victim identification (DVI) to disaster victim management (DVM): a necessary evolution
}

\author{
Calle Winskog $\cdot$ Michael Tsokos $\cdot$ Roger W. Byard
}

Accepted: 21 October 2011 / Published online: 22 January 2012

(C) Springer Science+Business Media, LLC 2012

This issue of Forensic Science, Medicine and Pathology presents a wide range of papers that deal with all aspects of disaster victim identification (DVI). The focus of many of the submissions has been on the expanding role of individual disciplines, the refining and integration of services, the formulation and implementation of international protocols, and the overview of processes to ensure that they are fulfilling their role appropriately. In short, this issue demonstrates the evolution of simple victim identification into the complex integrated approach that is now seen in so many of these events. It encompasses all aspects of such exercises that should now be included under the broader umbrella of disaster victim management (DVM), rather than merely identification. This issue deliberately contains many papers that do not represent original research, but instead summarize approaches to situations and methodology. This resulted from a decision by the editors to make this issue useful as a handbook for developing local DVI/M programs, in addition to being able to be taken to disaster areas as a practice manual.

Previous papers in the journal have dealt with practical aspects of constructing facilities in disaster areas, as well as on the problems that may arise from difficult work being conducted in under-resourced and sometime isolated locations by a large number of individuals with different

C. Winskog $\cdot$ R. W. Byard $(\bowtie)$

Discipline of Anatomy and Pathology, Level 3 Medical School

North Building, The University of Adelaide, Frome Road,

Adelaide, SA 5005, Australia

e-mail: roger.byard@sa.gov.au

M. Tsokos

Institute of Legal Medicine and Forensic Sciences, Charité

University, Turmstr. 21 (Haus L), 10559 Berlin, Germany nationalities, languages and experience $[1,2]$. In this issue the scope of topics has expanded considerably.

One of the fundamental requirements in disaster situations with multiple fatalities is the correct identification of victims [3]. Original papers in this issue that provide data to improve the evaluation of victims include an approach to age estimation in children based on an assessment of both dental and cervical vertebral maturation [4] and an examination of teeth and cranial size in assisting with the determination of gender [5]. A Commentary by Bassed gives an overview of methods of age estimation [6] and a Letter to the Editor by Wikwanitkit [7] draws attention to possible confounders of age estimation in children.

The potential roles of experts in particular fields have been reviewed for anthropologists [8], biologists [9], dentists [10] and pathologists [11]. Training and education in DVI/M is something that is often discussed, but which is usually undertaken at a local level without the benefit of established guidelines or an agreed upon philosophical approach. Winskog et al. [12] discuss an educational approach to DVI/M with Rutty et al. [13] providing suggestions for organizers of DVI/M training events on how to increase the training value for participants. A template for setting up an emergency mortuary facility is provided by Eitzen and Zimmerman [14].

Several papers deal with specific situations. For example, Schou and Knudsen [15] discuss the work of Danish teams in Thailand following the 2004 tsunami, and one of the guest editors, Calle Winskog, reports on issues that arose with the identification of the remains of a group of African men, victims of human trafficking, who were found in a boat drifting in the Caribbean, and also on the approach to DVI/M situations that occur in underwater environments [16, 17]. Although the paper by Hoyer et al. [18] only deals with two cases, it clearly demonstrates how 
useful integration of autopsy findings with CT may be in the evaluation of victims of aeroplane crashes. The role of DVI in multiple fatalities from vehicle crashes is described by Manhart et al. [19]. A striking "Images in Forensics" graphically shows putrefactive rigor mortis in drowning victims of the tsunami who were exposed to tropical temperatures [20].

The need for establishing and maintaining standards at all stages of the identification process, from securing reliable antemortem data to repatriating remains to families, is addressed by Lessig and Rothschild [21] in a paper which emphasizes the significance of the work of the Interpol Standing Committee on DVI. An equally important aspect of successful management of identification procedures is on-site quality management. Decisions and processes must be regularly checked to ensure that identifications have been correctly performed in a timely manner. Lake et al. have extrapolated their experience with quality management in an odontology setting to encompass all other areas of DVM. They emphasize the need for a stable chain of command that ensures that current scientific techniques and protocols are followed with regular review of standard operating procedures. Adequate staff training and briefing are also stressed [22]. A previously published method for measuring the error rate of an identification exercise is the "Correction of Failures," or CF, index, which is calculated quite simply as the total number of cases/specimens that have had to be re-examined as a percentage of the total number of cases/specimens examined. A CF index close to $100 \%$ indicates inefficient practice compared to one with minimal errors requiring very few re-examinations that would be close to $0 \%$; i.e. the lower the index, the more effective the primary identifications [23].

It is disturbing that many issues involving occupational health and safety have often been neglected in DVI/M situations, particularly in the early stages of the process when infrastructure may be rudimentary and the work load may be at its highest and most disorganized. Jacobsen et al. deal with possible health issues that arose following the south-east Asian tsunami and provide an approach to the pre- and post-deployment medical evaluation of personnel [24]. Given the exposure of foreign teams to asbestos at the Khao Lak site in Thailand when foundations were being dug for a temporary mortuary after the tsunami in early 2005, deploying authorities may be obliged to continue monitoring for a number of years.

DVI/M is increasingly becoming recognized as a subdiscipline of forensic practice. It is hoped that this special issue of Forensic Science, Medicine and Pathology will help to focus attention on the diversity of disciplines that may be involved, and on the need for an academic approach, with the formulation of rigorous international protocols that ensure the highest standards of scientific investigation and analysis. When a disaster occurs that requires professional intervention, a coordinated and considered approach should be adopted rather than $a d h o c$ and unauthorized mobilization of variably trained individuals and teams that has sometimes occurred in the past. The papers in this issue illustrate this point with contributions by individuals who have considerable experience, emphasizing the need for a carefully integrated response. The editors also hope that papers in this issue will increase the level of understanding amongst professionals involved in the field of DVI/M, and that this will lead to better coordination between disciplines when working together towards the important mutual goals of victim location, preservation, identification and repatriation.

\section{References}

1. Byard RW, Cooke C, Leditschke J. Practical issues involved in setting up temporary mortuaries after mass disasters. Forensic Sci Med Pathol. 2006;2:59-61.

2. Byard RW, Winskog C. Potential problems arising during international disaster victim identification exercises. Forensic Sci Med Pathol. 2010;6:1-2.

3. Rutty GN, Byard RW, Tsokos M. The tsunami. An environmental mass disaster. Forensic Sci Med Pathol. 2005;1:3-8.

4. Timmins K, Liversidge H, Farella M, Herbison P, Kieser J. The usefulness of dental and cervical maturation stages in New Zealand children for disaster victim identification. Forensic Sci Med Pathol. 2012. doi:10.1007/s12024-011-9251-8.

5. Thapar R, Angadi PV, Hallikerimath S, Kale AD. Sex assessment using odontometry and cranial anthropometry: evaluation in an Indian sample. Forensic Sci Med Pathol. 2012. doi:10.1007/s120 24-011-9247-4.

6. Bassed R. Advances in forensic age estimation. Forensic Sci Med Pathol. 2012. doi:10.1007/s12024-011-9280-3.

7. Wiwanitkit V. Skeletal X-ray and dental methods in child victims of the Southeast Asian Tsunami. Forensic Sci Med Pathol. 2012. doi:10.1007/s12024-011-9242-9.

8. Mundorff AZ. Integrating forensic anthropology into disaster victim identification. Forensic Sci Med Pathol. 2012. doi:10. 1007/s12024-011-9275-0.

9. Montelius K, Lindblom B. DNA-analysis in disaster victim identification. Forensic Sci Med Pathol. 2012. doi:10.1007/ s12024-011-9276-z.

10. Berketa JW, James H, Lake A. Forensic odontology involvement in disaster victim identification. Forensic Sci Med Pathol. 2012. doi:10.1007/s12024-011-9279-9.

11. Schuliar Y, Knudsen PJT. Role of forensic pathologists in mass disasters. Forensic Sci Med Pathol. 2012. doi:10.1007/s12024011-9300-3.

12. Winskog C, Tonkin A, Byard RW. The educational value of disaster victim identification (DVI) missions-transfer of knowledge. Forensic Sci Med Pathol. 2011. doi:10.1007/s12024011-9259-0.

13. Rutty G, Rutty E. Did the participants of the mass fatality exercise Operation Torch learn anything? Forensic Sci Med Pathol. 2011. doi:10.1007/s12024-010-9218-1.

14. Eitzen D, Zimmermann A. Setting up an off-site Emergency Mortuary Facility (EMF) to deal with a DVI incident. Disaster Victim Management (DVM). Forensic Sci Med Pathol. 2012. doi: 10.1007/s12024-011-9310-1. 
15. Schou MP, Knudsen PJT. The Danish disaster victim identification effort in the Thai tsunami-organisation and results. Forensic Sci Med Pathol. 2012. doi:10.1007/s12024-011-9297-7.

16. Winskog C. Underwater disaster victim identification: the process and the problems. Forensic Sci Med Pathol. 2011. doi:10.1007/ s12024-011-9271-4.

17. Winskog C. DVI missions in the Caribbean-the practical aspects of disaster victim identification. Forensic Sci Med Pathol. 2011. doi:10.1007/s12024-011-9273-2.

18. Høyer CB, Nielsen TS, Nagel LL, Uhrenholt L, Boel LWT. Investigation of a fatal airplane crash: autopsy, computed tomography, and injury pattern analysis used to determine who was steering the plane at the time of the accident. A case report. Forensic Sci Med Pathol. 2012. doi:10.1007/s12024-011-9239-4.

19. Buettner A. Disaster victim identification: experiences of the "Autobahn A19" disaster. Forensic Sci Med Pathol. 2012. doi: 10.1007/s12024-011-9307-9.
20. Tsokos M, Byard RW. Putrefactive "rigor mortis". Forensic Sci Med Pathol. 2012. doi:10.1007/s12024-011-9232-y.

21. Lessig R, Rothschild M. International Standards in cases of mass disaster victim identification (DVI). Forensic Sci Med Pathol. 2012. doi:10.1007/s12024-011-9272-3.

22. Lake AW, James H, Berketa JW. Disaster victim identification: quality management from an odontology perspective. Forensic Sci Med Pathol. 2012. doi:10.1007/s12024-011-9286-x.

23. Byard RW, Winskog C. Quality assurance in disaster victim identification (DVI) exercises (letter). J Forensic Sci. 2010;55:1135.

24. Huusom AJ, Agner T, Backer V, Ebbehøj N, Jacobsen P. Skin and respiratory disorders following the identification of disaster victims in Thailand. Forensic Sci Med Pathol. 2012. doi: 10.1007/s12024-011-9283-0. 